\title{
MOTIONS OF A LANDING CRAFT IN A FLOODED WELL DOCK - EFFECT OF WELL DOCK DESIGN
}

\author{
B. Cartwight, M. Renilson and G. Macfarlane, Australian Maritime College, Australia. \\ D. McGuckin, Pacific ESI, Australia. \\ S. Cannon, Defence Science \& Technology Organisation, Australia,
}

\begin{abstract}
One of the most important aspects of an amphibious ship is the ability to safely and swiftly transport and transfer large numbers of troops and their associated equipment from sea to shore. Such transfers are usually conducted using landing craft, which are loaded using a flooded well dock at the stern of the ship.
\end{abstract}

Hence, the behaviour of landing craft within the flooded well dock is of critical importance to the operators of an amphibious ship.

This paper describes, and presents results from, an investigation into the effect of the design of the well dock on the motions of a landing craft when operating in a seaway.

\section{INTRODUCTION}

The purpose of an amphibious ship is its ability to safely and swiftly transport large numbers of troops and their associated equipment from place to place, including transferring them from the ship to the shore. These transfers are usually conducted using landing craft because suitable berthing facilities are generally not available, and the quantity of equipment makes helicopter transfer difficult, if not impossible.

The ability to load landing craft from the amphibious ship at sea is therefore clearly a very important element in the effectiveness and efficiency of the procedure, with the maximum sea state where this can be accomplished safely being of paramount importance. Consideration of this aspect is a key element in the design of both the amphibious ship and the landing craft.

To make this process easier, and to increase the sea state that it can be conducted in, use is often made of the concept of a flooded well dock at the aft end of the amphibious ship (LPD). The limiting operational issue then becomes the motion of the landing craft within that dock. With this being particularly difficult to predict without using physical model experiments the design of an optimal dock/landing craft combination is neither easy nor inexpensive.

This paper investigates advanced numerical methods that aim to address these difficulties by working in a virtual, computational, space.

\section{SMOOTH PARTICLE HYDRODYNAMICS (SPH)}

Smoothed Particle Hydrodynamics (SPH) is a numerical technique where the material is described by a set of points, and all the points are free to move independently of their neighbours. This freedom of movement is attractive where large relative deformations of adjacent elements are expected, as in the analysis of such phenomena as the fracture of brittle materials or turbulent fluid flows. In comparison, a mesh-based finite element (FE) approach often runs into severe numerical difficulty when the mesh undergoes severe distortions as it tries to adequately represent the resulting large relative deformations.

Based on a point-mass approach, the material information in an SPH formulation travels with the point mass as it moves, according to Newton's Second Law, through the model domain. The local properties of any specific particle are defined by the weighted summation of the same corresponding properties belonging to its neighbouring particles. This is the so-called 'smoothing' of the local properties, from which comes the overall term "Smoothed Particle Hydrodynamics".

SPH, reviewed comprehensively in (Monaghan, 1992), were proposed some 30 years ago for astrophysics problems independently by two groups of researchers (Lucy, 1977 and Gingold \& Monaghan, 1977). Out of that pioneering work came a grid-less, Lagrangian technique in which the fluid is modelled with a set of discrete, interacting, particles instead of a solid element mesh. Since then, SPH techniques have been used in many fields of physics, including the behaviour of incompressible fluids.

Of specific interest to the naval fraternity is the more recent work, largely with in-house software codes and (primarily) in two dimensions, by Tulin \& Landrini (2001), Naito \& Sueyoshi (2002), Colagrossi et al (2004), Dalrymple \& Rogers (2006), Rogers et al (2003), Doring et al (2004), and Fontaine (2000) to name but a few. These landmark papers have demonstrated feasible results using SPH techniques for scenarios common in ship hydrodynamics. 
Being a Lagrangian technique, SPH can be readily linked to standard FE formulations. Such a hybridised FE and SPH formation is extremely well suited to fluid-structure interaction (FSI) problems because these scenarios typically involve large relative displacements and $\mathrm{SPH}$ conveniently overcomes many of the material interface problems between a structure and the surrounding fluid.

SPH features were incorporated into the commercial PAM-SHOCK $^{\mathrm{TM}}$ (2007) explicit FE code in the early 1990 s, it being exploited originally to model the highspeed impact of space debris onto satellites (Groenenboom, 1997, and Kamoulakos \& Groenenboom, 1998). SPH have since been added to PAM-CRASH, in which guise SPH has been used to investigate a broad range of three dimensional problems including complex ship motions (Cartwright et al, 2004), bird-strike impact on aircraft wings (McCarthy et al, 2004), and the crash landing onto water of a modern jetliner (Pentecote et al, 2003). Not only do some of the many commercial codes, in which SPH has now been implemented, mean wider access to thoroughly tested and well verified SPH implementations, but such codes also provide access to features such as industry-validated automatic time-step and contact algorithms to help ensure a stable result, a wide range of advanced material behaviour models, and the associated linkage with high quality graphical modelling and visualization tools.

With SPH techniques now available to those who would neither have the ability nor desire or resources to write the code themselves, a researcher or design professional can focus on the application of the technology to a specific scenario, as has been demonstrated in some recent work on yacht and ship motions (Cartwright, et al, 2006a), and related work on landing craft in mother ships (Cartwright, et al, 2006b).

\section{NUMERICAL MODEL SETUP}

For simplicity all the simulations were conducted using 2D models, shown in Figure 1. Although, in principle, 3D models could be used for this problem, the significant increase in computing effort was not deemed necessary as the cases being studied corresponded to head seas.

The models were constructed at model scale, and hence the LPD and landing craft dimensions correspond to those listed in the Model Experiment section below.

For both cases the LPD vessel was held at a fixed location in the fore and aft direction, and the heave and pitch motions were defined according the experimental result.

A beach was located 6.1 metres aft of the LPD to minimise any reflected waves generated by the LPD movements. To aid in absorbing waves on the beach, 6 vertical rows of alternate SPH elements over the beach were restricted to vertical movements only.
The interface between the SPH water and the FE ship was defined by an industry standard penalty-method contact interface. This ensured that the SPH remain on the exterior of the ship structures, yet the momentum is automatically conserved during any collision events between the SPH and the shell elements of the ship structures.

The computational effort required is proportional to the number of the SPH particles, and this is of course influenced by the volume of water to be modelled and the size of the SPH particles used. From a practical perspective the SPH particles needed to be of a size sufficiently small to fit between the landing craft and the well dock floor.

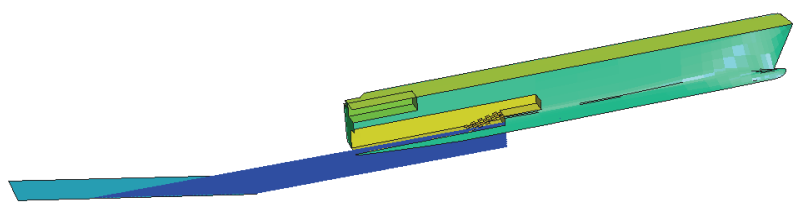

Figure 1: Two-dimensional numerical model setup - no landing craft shown.

\section{MODEL EXPERIMENTS}

Physical models of a generic amphibious ship and landing craft were constructed at a scale of 1:22 and a series of hydrodynamic experiments were conducted within the Australian Maritime College's Model Test Basin. Initial experiments were conducted to quantify the wave environment within, and at the entrance to, the well dock for a range of regular and irregular wave conditions.

A further series of tests, which included a model of a landing craft at specific locations within the well dock (at two different load conditions), were conducted to determine the vertical motions of the craft relative to the amphibious ship.

All irregular waves were generated to the JONSWAP wave energy spectrum with peak enhancement of 3.3. The spectra are typical of those expected in fetch limited coastal waters. For all experiments the water depth within the test basin remained constant to represent a full scale water depth of 15 metres.

A drawing showing the design of the well dock is shown in Figure 2. Note that a porous beach was included at the end of the well dock. The vertical displacement of each model was measured using displacement transducers. All water surface elevations were measured using capacitance type wave probes, located as shown in Figure 3. The location of the landing craft within the well dock is shown in Figure 4.

A photograph taken during the model tests in shown in Figure 5, where the model of the landing craft can be seen within the well dock. 


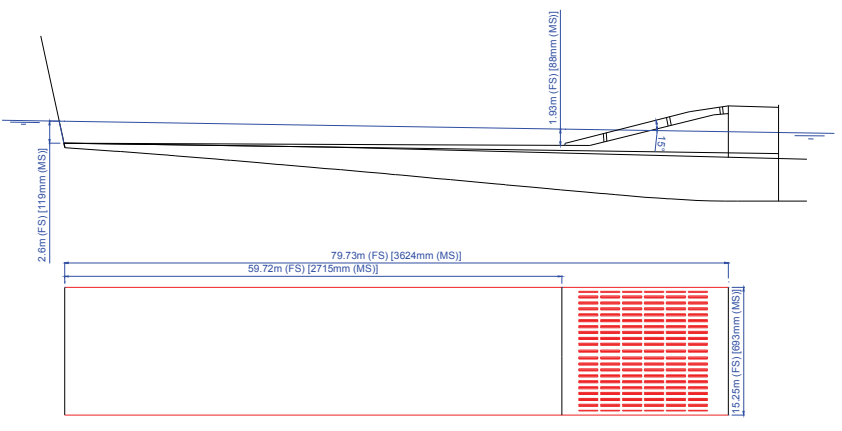

Figure 2: Well dock design.

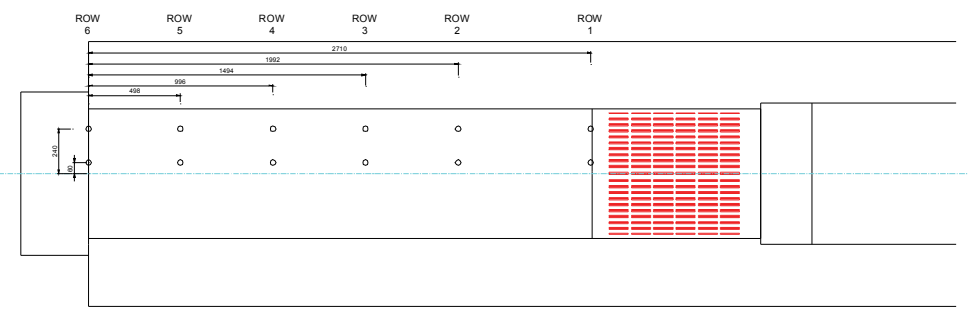

Figure 3: Location of wave probes within the well dock.

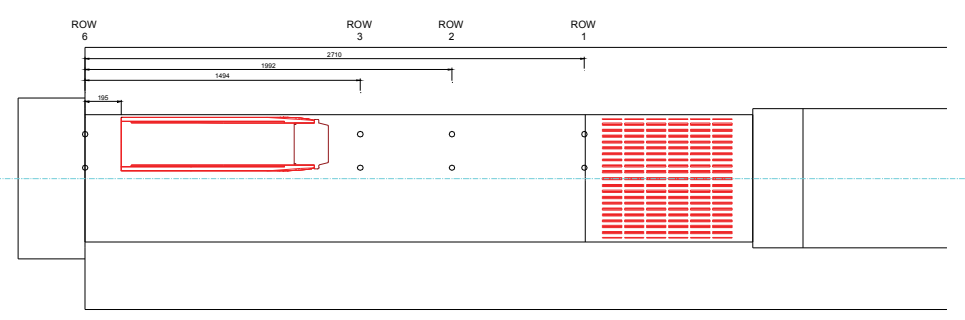

Figure 4: Location of landing craft and wave probes within the well dock.

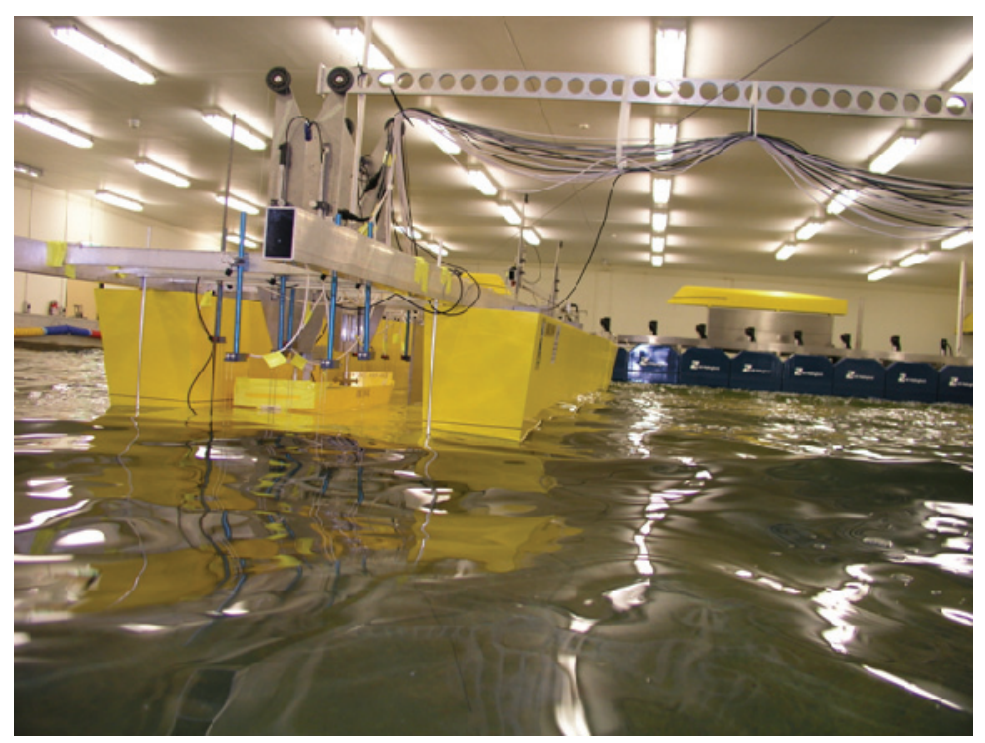

Figure 5: Photograph from the model tests. The landing craft model can be seen within the well dock 


\section{COMPARISON BETWEEN EXPERIMENTS AND NUMERICAL PREDICTIONS}

In order to compare the predictions using $\mathrm{SPH}$ with the experimental results, the LPD was assumed to be in calm water and driven using motions measured in the experiments in waves. This then resulted in waves being generated in the dock which were compared to those measured in the experiments.

An SPH spacing of $33 \mathrm{~mm}$, model scale, was used, with 4304 SPH elements. Computation time for 60 seconds of simulation time was approximately 1 hour on a $3 \mathrm{GHz}$ Pentium pc.

For ease in the calculations the LPD was originally out of the water, and was lowered into the water at the start of the simulation. This meant that the water flooded into the well dock. Then, the heave and pitch motions were forced onto the LPD model.

The simulated geometry is shown in Figure 6.
An important point to note is the way that the beach is represented by a course mesh which allows the SPH to pass through. This technique may need further refining.

The model scale wave elevations as functions of time are shown in Figures 7 and 8 for the wave probe near the entrance to the well dock and the wave probe near the beach respectively. Results presented here are based on a representative 40 second time domain model scale LPD response in sea state 4 .

As can be seen, the simulations agree fairly well for the wave probe near the entrance, but are less accurate for the wave probe near the beach. This may be due to the beach not behaving correctly as a consequence of the simplified way in which it was represented.

The predicted response of the Landing Craft near the entrance to the dock is compared with the measured result for a different time realisation in Figure 9. The poor correlation at the beginning of the time sample was due to the landing craft still responding to the dynamic effects of placing the landing craft at the correct location. After this time the correlation is reasonable.

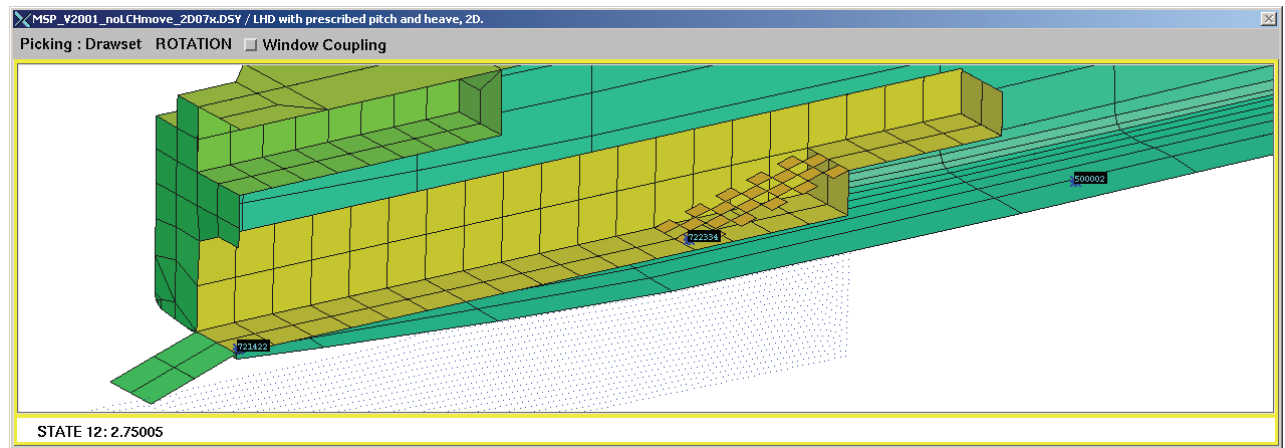

Figure 6: Well Dock Beach construction - coarse mesh to allow SPH to pass through

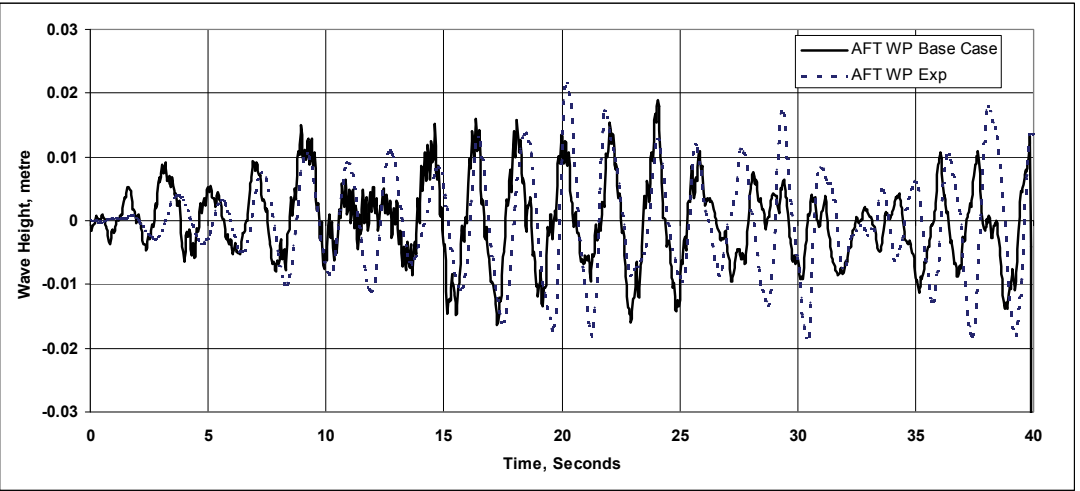

Figure 7: Simulation (solid) and Experimental (dashed) wave probe traces at the entrance to the "Base Case" generic LPD and well dock (model scale). 


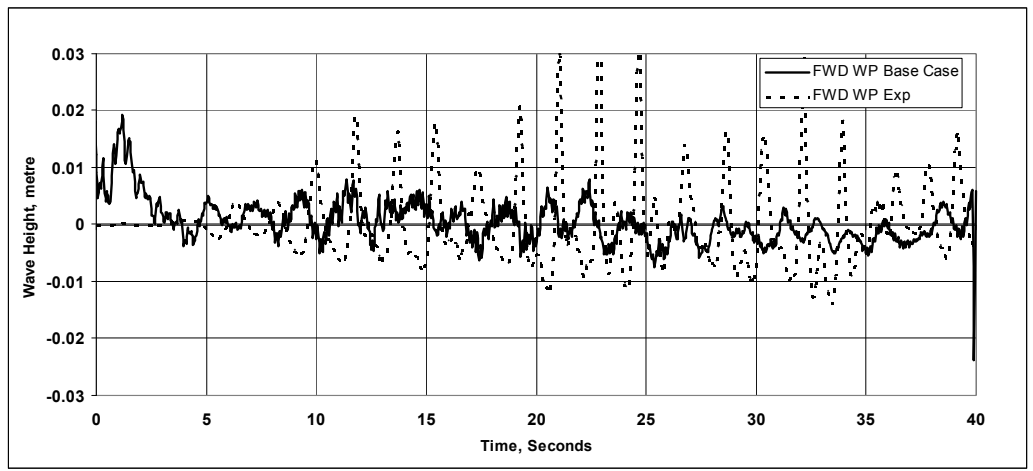

Figure 8: Simulation (solid) and Experimental (dashed) wave probe traces adjacent the beach within the well dock of the "Base Case" generic LPD (model scale).

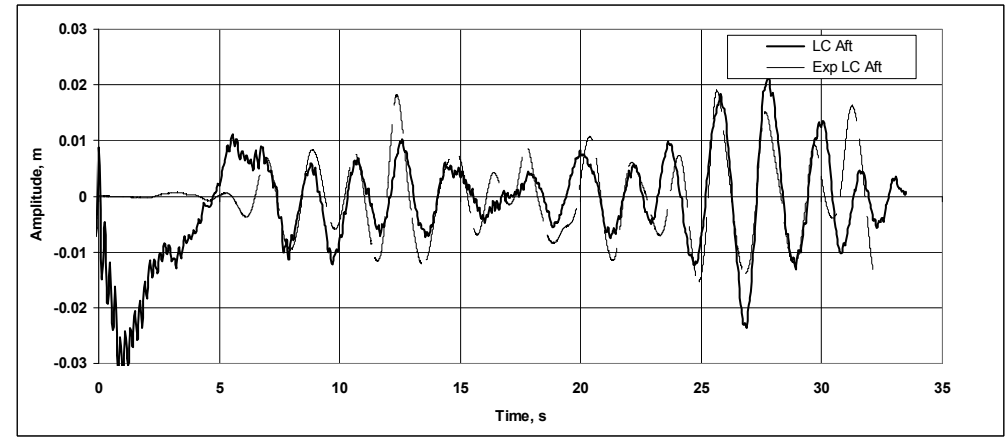

Figure 9: Experimental and simulated landing craft heave at the stern of the landing craft (model scale).

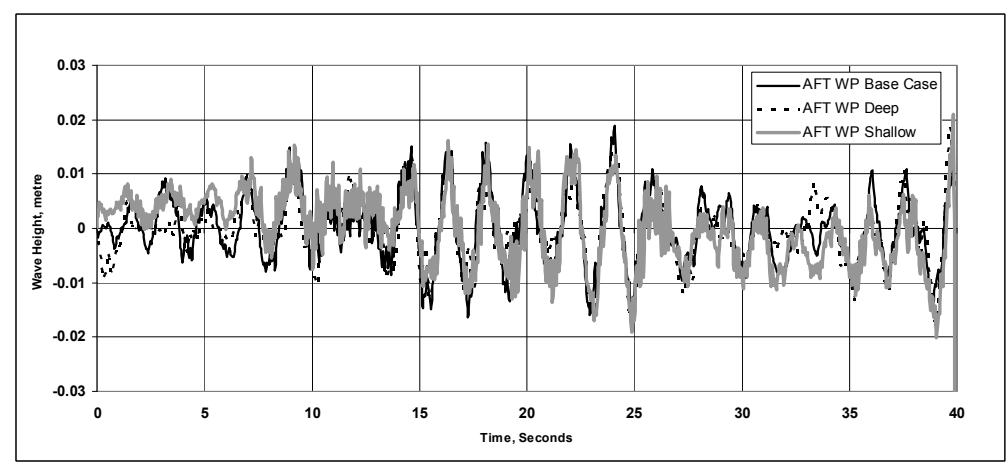

Figure 10: Simulated wave heights in different well dock depths. "Deep" was $0.5 \mathrm{~m}$ deeper than the Base Case, and "Shallow" was $0.5 \mathrm{~m}$ less deep than the Base Case.

\section{EFFECT OF DOCK DESIGN PARAMETERS}

Using the technique outlined above the wave elevations at the entrance to the dock were obtained for the following three geometrical changes to the dock:

1. dock depth;

2. slope of dock bottom; and

3. configuration of dock door.

The effect of the depth of the dock is shown in Figure 10. As can be seen this has little influence on the wave heights at the entrance, suggesting that it will have little influence on the motions of the landing craft at this position.

The effect of the slope of the bottom of the dock is shown in Figure 11. The floor of the Base Case was rotated about the entrance of the well dock by $+1.5^{\circ}$ to produce the "slope up" geometry, and by $-1.5^{\circ}$ to produce the "slope down" geometry.

As can be seen, the results suggest that a "slope down" well dock floor may produce larger waves at the entrance than the Base Case. This effect is more noticeable for the duration of large waves, where a lower trough is contributing to the larger wave height. 


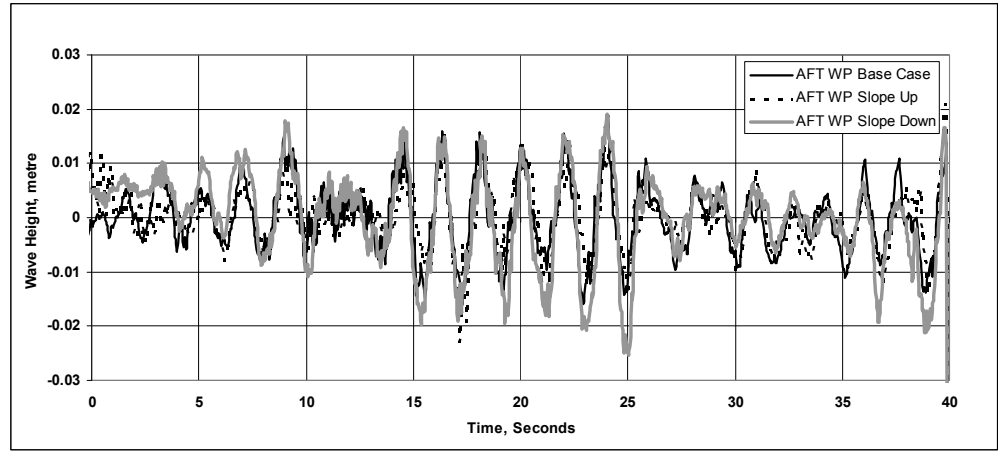

Figure 11: Simulated wave heights for varying the well dock geometry - "slope up" case had the beach shallower than the entrance, and "slope down" had the beach deeper than the entrance.

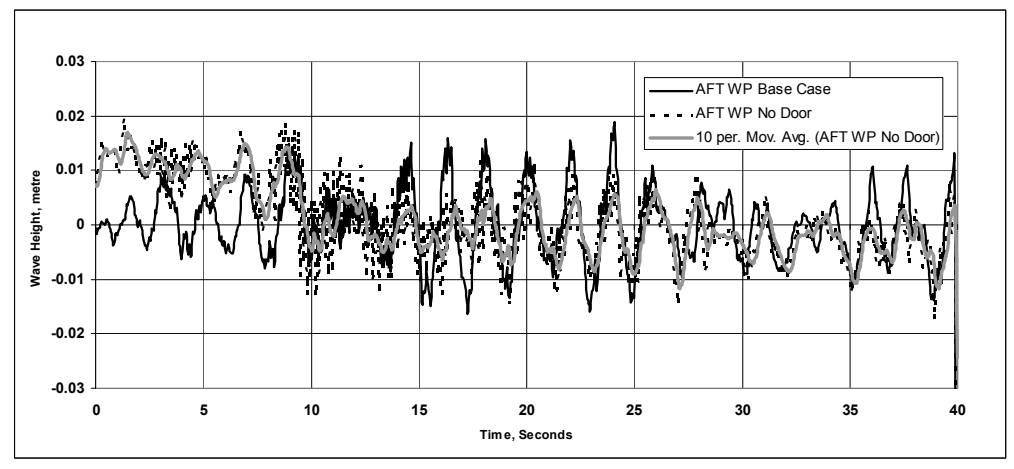

Figure 12: Simulated wave heights at the entrance to the well dock with and without the entrance door.

The effect of removing the outward facing rear door on the waves at the well dock entrance can be seen in Figure 12. It can be seen that the presence of the door appears to increase the waves in the dock.

\section{CONCLUDING COMMENTS}

This paper presents the results from a very limited investigation into the effect of the well dock geometry of a generic LPD using a 2D SPH technique. From these results the following very tentative conclusions can be drawn:

1. the waves in the dock (at least near the entrance) appear to be dominated by those generated by the motions of the LPD, rather than the ambient waves;

2. changing the depth of the dock has little influence on the waves at the entrance to the dock;

3. sloping the bottom of the dock up from the entrance forward appears to reduce the size of the waves at the entrance to the dock compared to either a level bottom, or a bottom sloping down from the entrance forward; and
4. the presence of an open outward sloping door appears to increase the size of the waves at the entrance to the dock.

\section{REFERENCES}

1. Cartwright B., Groenenboom P. H. L., McGuckin D., (2004b) 'A Novel Technique to Predict NonSteady Loads in Vessels in Severe Seas', In ISOPE 2004, 2004.

2. Cartwright B., McGuckin D., Turner T., Cannon S., (2006) 'The modeling of landing craft motions inside a flooded well dock using smoothed particle hydrodynamics', Pacific 2006: International Maritime Conference, 2006.

3. Cartwright B., Xia J., Cannon S., McGuckin D., Groenenboom P., (2004a) 'Prediction of Motions of Ships and Yachts by Smoothed Particle Hydrodynamics', High Performance Yacht Design, New Zealand, 2006.

4. Colagrossi A., Lugni C., Greco M., Faltinsen O., (2004) 'Experimental and numerical investigation of 2D sloshing with slamming.' In Proc. 19th 
International Workshop on Water Waves and Floating Body (IWWWFB), Italy, 2004.

5. Dalrymple R.A., Rogers B.D., (2006) 'Numerical modeling of water waves with the SPH method', Journal of Coastal Engineering, Volume 53, Issues 2-3, February 2006.

6. Doring $\mathrm{M}$, Oger $\mathrm{G}$, Alessandrini B, Ferrant $\mathrm{P}$, (2004) 'SPH Simulation of Floating Bodies in Waves', 23rd International Conference on Offshore Mechanics and Arctic Engineering, June 20-25, 2004, Vancouver, British Columbia, Canada.

7. Fontaine, E. (2000) 'On the use of Smoothed Particle Hydrodynamics to model extreme waves and their interactions with a structure', presented at Rogue Waves 2000, 29-30 November, Le Quartz, Brest, France.

8. Gingold R. A., Monaghan J. J., (1977) 'Smoothed Particle Hydrodynamics: Theory and Application to Non-Spherical Stars', Monthly Notices of the Royal Astronomical Society 181, 1977, 375-389.

9. Groenenboom P. H. L., (1997) 'Numerical Simulation of Hypervelocity Impact using the SPH Option in PAM-SHOCK', International Journal of Impact Engineering 20, 1997, 309-323.

10. Kamoulakos A., Groenenboom P. H. L., (1998) 'Moving form FE to SPH for Space Debris Impact Simulations - Experience with PAMSHOCK', in Proceedings of European Conference on Spacecraft Structures: Materials and Mechanical Testing, Braunschweig, Germany, 1998.

11. Lucy L. B., (1977) 'A Numerical Approach to the Testing of Fusion Process', The Astronomical Journal 88, 1977, 1013-1024.

12. McCarthy M.A., Xiao J.R., McCarthy C.T, Kamoulakos A., Ramos J., Gallard J.P. and Melito V., (2004) 'Modelling of Bird-strike on an Aircraft Wing Leading Edge Made from Fibre Metal Laminates - Part 2: Modelling of Impact with SPH Bird Model', Applied Composite Materials, Vol. 11, 2004, 317-340.

13. Monaghan J. J., (1992) 'Smoothed Particle Hydrodynamics', Annual Review of Astronomy and Astrophysics 30, 1992, 543-574.

14. Naito S., Sueyoshi M., (2002) 'A Numerical Analysis of Violent Free Surface Flow by Particle Method', ISOPE 2002.

15. PAM-CRASH ${ }^{\mathrm{TM}} / \mathrm{PAM}-\mathrm{SHOCK}{ }^{\mathrm{TM}}$ FE Code, (2007) Engineering Systems International, 94578 Rungis Cedex, France.
16. Pentecote N., Kohlgruber D., Kamoulakos A., (2003) 'Simulation of Water Impact Problems Using the Smoothed Particle Hydrodynamics Method', In: Groupement Régional Nord Pas de Calais pour la Recherche dans les Transports (G.R.R.T.) [Hrsg.], ICD03 International Crashworthiness and Design Symposium, GRRT

17. Rogers B.D., Dalrymple R.A., Gesteira M., Knio O., (2003) 'Smoothed Particle Hydrodynamics for Naval Hydrodynamics', Proc. Int. Workshop on Water Waves and Floating Bodies, 2003.

18. Tulin M.P., Landrini M., (2001) 'Breaking waves in the ocean and around ships', Proc. Twenty-Third Symposium on Naval Hydrodynamics (2001).

\section{ACKNOWLEDGEMENTS}

The technical assistance of Paul Groenenboom, and overall support of Argiris Kamoulakos, from ESI Group is invaluable to this work.

\section{AUTHOR'S BIOGRAPHIES.}

Bruce Cartwight is currently studying for a Master of Philosophy at the Australian Maritime College in the field of Ship Hydrodynamics. The study is aimed at developing techniques to use the Smoothed Particle Hydrodynamics as a tool for the naval fraternity. He has used explicit finite element software codes for over ten years, previously in the fields of bird-strike impact survivability predictions and manufacturing process simulations for the aerospace industry. He is generously supported in this work by Pacific ESI.

Martin Renilson is currently professor of hydrodynamics at the Australian Maritime College. He was formerly Technical Manager for the Maritime Platforms and Equipment group at QinetiQ.

Gregor Macfarlane completed a BE and MPhil in naval architecture from the Australian Maritime College (AMC). He is currently the Manager of the towing tank and shallow water basin at AMC where he coordinates all activities within these facilities. His main interest lies in the field of hydrodynamics with specific emphasis on vessel generated waves.

Damian McGuckin is the Managing Director of Pacific ESI. He has a strong mathematical and computational background, complemented by broad practical experience is using advanced technology in the aerospace, automotive, construction, and mining fields. His current research interests focus on the application of CAE technology for maritime and aerospace applications so that a better tool is available for the design professional to be then able to exploit advanced 
materials, manufacturing processes, and improved design methods.

Stuart Cannon is currently the head of Surface Ship Structural Management and the task leader for Surface Platform Systems at the Maritime Platforms Division of the Australian Defence Science and Technology Organisation. He is involved in research and providing advice to the Australian Defence Organisation on a variety of current and future projects. He is a naval architect and holds a $\mathrm{PhD}$ from Brunel University in the UK. 